\title{
Interferon consensus sequence-binding protein (ICSBP) promotes epithelial-to-mesenchymal transition (EMT)-like phenomena, cell-motility, and invasion via TGF- $\beta$ signaling in U2OS cells
}

\author{
JY Sung ${ }^{1}$, S-Y Park ${ }^{2}$, JH Kim ${ }^{3}$, HG Kang ${ }^{3}$, JH Yoon ${ }^{1}$, YS Na ${ }^{1}$, Y-N Kim ${ }^{*, 4}$ and B-K Park ${ }^{\star, 1}$
}

Interferon consensus sequence-binding protein (ICSBP) is a transcription factor induced by interferon gamma (IFN- $\gamma$ ) and a member of the interferon regulatory factor (IRF) family. ICSBP is predominantly expressed in hematopoietic cells and regulates the immune response and cell growth and differentiation. However, little is known about its function in non-hematopoietic cells. Here we show a novel function for ICSBP in epithelial-to-mesenchymal transition (EMT)-like phenomena (ELP), cell motility, and invasion in human osteosarcoma cell lines, including U2OS cells. IFN- $\gamma$ treatment induced ICSBP expression and EMT-like morphological change in U2OS cells, which were suppressed by ICSBP knockdown. To further investigate the role of ICSBP in ELP, we established a stable U2OS cell line that overexpresses ICSBP. ICSBP expression caused U2OS cells to have a more elongated shape and an increased vimentin and fibronectin expression. ICSBP expression also promoted adhesiveness, motility, and invasiveness of U2OS cells. ICSBP upregulated transforming growth factor (TGF)- $\beta$ receptors and activated TGF- $\beta$ signaling cascades, which were responsible for ELP as well as increased cell motility and invasion. In addition, ICSBP-induced TGF- $\beta$ receptor activation resulted in the upregulation of Snail. Knockdown of Snail attenuated the ICSBP-induced augmentation of cell motility and invasion. Upregulation of Snail, ELP, and increased invasion by ICSBP expression were also observed in other osteosarcoma cell lines, such as Saos-2 and 143B. Furthermore, ICSBP and TGF- $\beta$ receptor I were expressed in 45/54 $(84 \%)$ and $47 / 54(87 \%)$ of human osteosarcoma tissues, respectively, and showed significant correlation $(r=0.47, P=0.0007)$ with respect to their expression levels. Taken altogether, these data demonstrate a novel function for ICSBP in ELP, cell motility, and invasion through the TGF- $\beta$ and Snail signaling pathways.

Cell Death and Disease (2014) 5, e1224; doi:10.1038/cddis.2014.189; published online 15 May 2014

Subject Category: Cancer

Epithelial-to-mesenchymal transition (EMT) is an essential process during embryonic development. ${ }^{1}$ EMT is also involved in pathogenesis, such as organ fibrosis and cancer metastasis. ${ }^{2}$ During EMT, cells redistribute or downregulate junction proteins, including E-cadherin and tight junction protein 1 (ZO-1), and re-express mesenchymal marker proteins, such as vimentin and fibronectin. These molecular changes result in a decrease in cell-to-cell junctions and an increase in cell motility. ${ }^{3}$ EMT can be induced by multiple cytokines and growth factors, including transforming growth factor- $\beta$ (TGF- $\beta)^{4}{ }^{4}$

TGF- $\beta$ binds TGF- $\beta$ receptor II (TGF- $\beta$ RII), which then phosphorylates and activates TGF- $\beta$ receptor I (TGF- $\beta$ RI). Activated TGF- $\beta$ RI phosphorylates Smad transcription factors (RSmads). Activated RSmads bind Smad4 and regulate the expression of various target genes, including EMT- and cell motility-related genes. ${ }^{5}$ TGF- $\beta$ upregulates transcription factors, such as the zinc finger proteins Snail, Slug, Zeb1, and Zeb2 as well as the basic helix loop helix factors, Twist, and E47. ${ }^{6}$ These repressors bind the E-box in the E-cadherin gene promoter and thereby repress E-cadherin expression.

Interferon consensus sequence-binding protein (ICSBP), also known as the interferon regulatory factor-8 (IRF-8), is a transcription factor of the IRF family and induced by IFN- $\gamma$ in the immune system. ${ }^{7}$ ICSBP has an essential role in macrophage maturation. ${ }^{8}$ ICSBP binds the IFN-stimulated response element and regulates gene expression involved in

\footnotetext{
${ }^{1}$ Center for Pediatric Oncology, National Cancer Center, Goyang-si, Gyeonggi-do, Korea; ${ }^{2}$ Department of Pathology, National Cancer Center, Goyang-si, Gyeonggi-do, Korea; ${ }^{3}$ Orthopaedic Oncology Clinic, National Cancer Center, Goyang-si, Gyeonggi-do, Korea and ${ }^{4}$ Comparative Biomedicine Research Branch, National Cancer Center, Goyang-si, Gyeonggi-do, Korea

${ }^{*}$ Corresponding author: Y-N Kim, Comparative Biomedicine Research Branch, National Cancer Center, 323 Ilsan-ro, Ilsandong-gu, Goyang-si, Gyeonggi-do 410-769, Korea. Tel: + 8231920 2415; Fax: + 8231920 2468; E-mail: ynkim@ncc.re.kr

or B-K Park, Center for Pediatric Oncology, National Cancer Center, 323 Ilsan-ro, Ilsandong-gu, Goyang-si, Gyeonggi-do 410-769, Korea. Tel: + 82 31 920 1651; Fax: + 8231920 1244; E-mail: bkpark@ncc.re.kr

Keywords: ICSBP; EMT-like phenomena; TGF- $\beta$; Snail; cell motility; invasion

Abbreviations: ICSBP, interferon consensus sequence-binding protein; IFN- $\gamma$, interferon gamma; IRF, interferon regulatory factor; IL-1 $\beta$, interleukin-1 beta; TNF- $\alpha$, tumor necrosis factor alpha; EMT, epithelial-to-mesenchymal transition; ELP, EMT-like phenomena; TGF- $\beta$, transforming growth factor beta; TGF- $\beta$ RI, TGF- $\beta$ receptor I; TGF- $\beta$ RII, TGF- $\beta$ receptor II; Smad, Sma and Mad proteins; RSmad, receptor-regulated Smad; STAT1, signal transducers and activators of transcription 1; ERK, extracellular signal-regulated kinase; PI3K, phosphoinositide 3 kinase; RT-PCR, reverse transcription-PCR; ECIS, electrical cell-substrate impedance sensing; HUVEC, human umbilical vein endothelial cell; FBS, fetal bovine serum

Received 25.11.13; revised 23.2.14; accepted 31.3.14; Edited by Y Shi
} 
myeloid and B-cell differentiation. ${ }^{9}$ ICSBP-deficient mice (ICSBP $^{-1-}$ ) develop a disease resembling human chronic myeloid leukemia. ${ }^{10}$ In addition, myeloid cells derived from ICSBP $^{-1-}$ mice show an increased resistance to apoptosis, whereas ICSBP overexpression in human U937 monocytic cells renders them sensitive to apoptosis. ${ }^{11}$ Most studies have focused on the role of ICSBP in hematopoietic cells. A recent report demonstrated ICSBP downregulation in non-hematopoietic tumors, including nasopharyngeal, esophageal, and multiple other carcinomas, ${ }^{12}$ suggesting that ICSBP may function as a tumor suppressor in various tumors. In addition to its tumor-suppressive effects, we recently demonstrated that ICSBP expression enhances cell proliferation via TGF- $\beta$ receptor-TAK (TGF- $\beta$-activated kinase) signaling pathways in leukemic HL-60 cells. ${ }^{13}$ Therefore, it is possible that ICSBP may not function entirely as a tumor suppressor and its effect on cell growth may differ depending on cellular context.

In addition to a growth regulatory role of ICSBP, ICSBP deficiency is associated with cell spreading and adhesiveness in macrophages. ${ }^{14}$ ICSBP repression has been observed in the metastatic colon cancer cells but not in primary cancer cells. ${ }^{15}$ On the other hand, a mixture of interleukin-1 $\beta$ (IL-1 $\left.\beta\right)$, tumor necrosis factor- $\alpha(\mathrm{TNF}-\alpha)$, and IFN- $\gamma$ augments EMT and cell migration through enhanced TGF- $\beta$ signaling in A549 lung epithelial carcinoma. ${ }^{16}$ These data indicate that ICSBP functions as either a positive or a negative regulator in tumor metastasis depending on cell types.

In the present study, we investigated a possible role for ICSBP in EMT-like phenomena (ELP) induction and cell motility in U2OS osteosarcoma cells as well as a possible mechanism underlying this process. We demonstrated that ICSBP expression in U2OS cells induces more elongated cell shape with less cell-cell contact. ICSBP also enhances cell motility and invasion through Snail expression mediated by the activation of TGF- $\beta$ receptor. These data provide evidence for a novel ICSBP function in the acquisition of a phenotype related to metastasis in osteosarcoma cells.

\section{Results}

IFN- $\gamma$ induces ICSBP expression, which results in ELP in U2OS cells. To test whether IFN- $\gamma$ induces ICSBP in osteosarcoma cells, U2OS cells were treated with IFN- $\gamma$. ICSBP protein was detected in the absence of IFN- $\gamma$, and it was upregulated in a dose-dependent manner with IFN- $\gamma$ treatment (Figure 1a). Phosphorylated signal transducers and activators of transcription 1 (pSTAT1) was also increased dose-dependently with IFN- $\gamma$ treatment, which suggests that IFN- $\gamma$ treatment activated Janus kinase/STAT1/ICSBP pathway in U2OS cells. ${ }^{9}$ Interestingly, IFN- $\gamma$ treatment caused EMT-like cell morphology with decreased cell-cell contact and more elongated cell shape (Figure 1b). In addition, IFN- $\gamma$ altered the expression levels of EMT molecules: ZO-1 was decreased while fibronectin and vimentin were increased by IFN- $\gamma$ treatment (Figure 1c). Transfection of U2OS cells with small interfering RNA (siRNA) specific for ICSBP (si-ICSBP) knocked down ICSBP expression in the IFN- $\gamma$-treated cells with no change in pSTAT1 level, indicating that STAT1 is upstream of ICSBP (Figure 1d), and knockdown of ICSBP inhibited the morphological changes induced by IFN- $\gamma$
(Figure 1e). To test whether IFN- $\gamma$ treatment stimulates cell motility, we performed a wound-healing assay. IFN- $\gamma$ treatment enhanced cell motility, which was blocked by ICSBP knockdown (Figure 1f). These data indicate that ICSBP is induced by IFN- $\gamma$ in U2OS cells and its expression is linked to morphological changes seen in EMT and enhanced cell motility, which we named ELP.

ICSBP overexpression enhances TGF- $\beta$ signaling and induces ELP in U2OS cells. To further investigate the association of ICSBP with cell morphological changes and enhanced motility, we established a U2OS cell line overexpressing human ICSBP (ICSBP cells). Because ICSBP construct contained V5 tag, anti-ICSBP antibody detected both endogenous and exogenous ICSBP (lower and upper ICSBP band, respectively, in the ICSBP cells) (Figure 2a, right panel), while anti-V5 antibody detected only exogenous ICSBP (Figure 2a, left panel). We also found that ICSBP was localized in the nucleus (Figure 2b). Next, we examined the effect of ICSBP expression on cell morphology and on the levels of EMT-related proteins. As expected, ICSBP expression induced a morphological change with more elongated shape (Figure 2c) and decreased ZO-1 and E-cadherin but increased vimentin and fibronectin levels (Figure 2d). Moreover, ZO-1 and $\mathrm{E}$-cadherin levels were recovered, whereas vimentin and fibronectin levels were downregulated in ICSBP knockdown cells. TGF- $\beta$ is a critical EMT inducer, and previously, we demonstrated that ICSBP overexpression induces TGF- $\beta$ RI expression and activates TGF- $\beta$ signaling pathways. ${ }^{13}$ Therefore, we explored whether ICSBP-induced ELP is mediated by TGF- $\beta$ receptor activation. Consistent with our previous report, ${ }^{13}$ ICSBP overexpression induced both TGF- $\beta$ RI and RII in U2OS cells. In addition, basal phosphorylation levels of both Smad2 and Smad3 were increased in the ICSBP cells as compared with the Mock cells (Figure 2e). Non-Smad pathway molecules, such as extracellular signal-regulated kinase (ERK), AKT, and p38, were also activated by ICSBP. We investigated whether ICSBP regulates TGF- $\beta$ receptor expression in the upstream. TGF- $\beta$ receptor expression was reduced with ICSBP knockdown in ICSBP cells. However, TGF- $\beta$ RI knockdown did not affect ICSBP expression (Figure 2f). Consequently, Smad2 and Smad3 phosphorylation levels were also attenuated with si-ICSBP transfection in the ICSBP cells (Figure $2 \mathrm{~g}$ ). These data indicate that ICSBP induces ELP and upregulates TGF- $\beta$ receptor expression, with subsequent activation of TGF- $\beta$ receptor pathways.

Effects of ICSBP on TGF- $\beta$ receptor expression. To determine whether ICSBP increases TGF- $\beta$ RI at a transcriptional level, we examined its mRNA levels by reverse transcription-PCR (RT-PCR). As shown in Figure 3a, TGF- $\beta$ $\mathrm{RI}$ mRNA levels were upregulated in the ICSBP cells. We further examined whether TGF- $\beta$ RI promoter is activated in the ICSBP cells. Mock and ICSBP cells were transiently transfected with reporter vectors, and promoter activities were deduced from quantitation of luciferase assays. Luciferase activities were increased more than twofold in the ICSBP cells compared with the Mock cells, raising the possibility that TGF- $\beta \mathrm{RI}$ promoter is activated by ICSBP (Figure $3 b$ ). Thus, we are currently investigating whether 

IFN- $\gamma$ (IU):

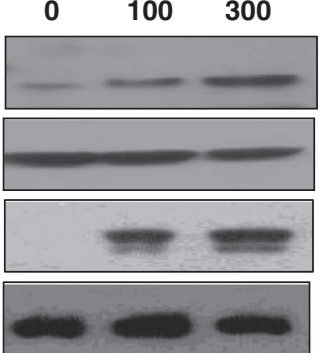

ICSBP

$\beta$-actin

PSTAT1

$\beta$-actin

\section{Cont IFN- $\gamma$}

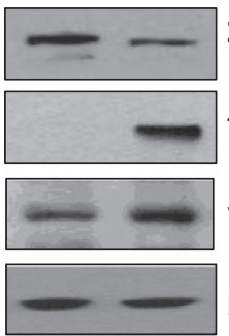

Zo-1

fibronectin

vimentin

$\beta$-actin b

Cont

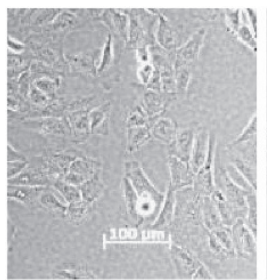

IFN- $\gamma$

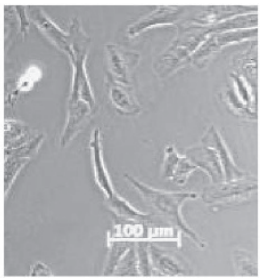

d
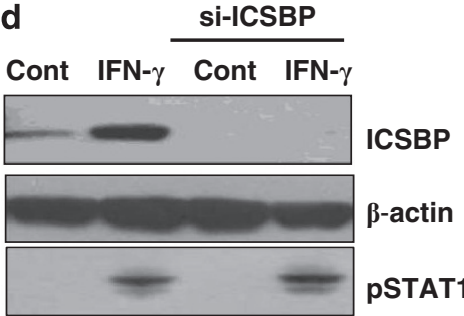

$\beta$-actin e
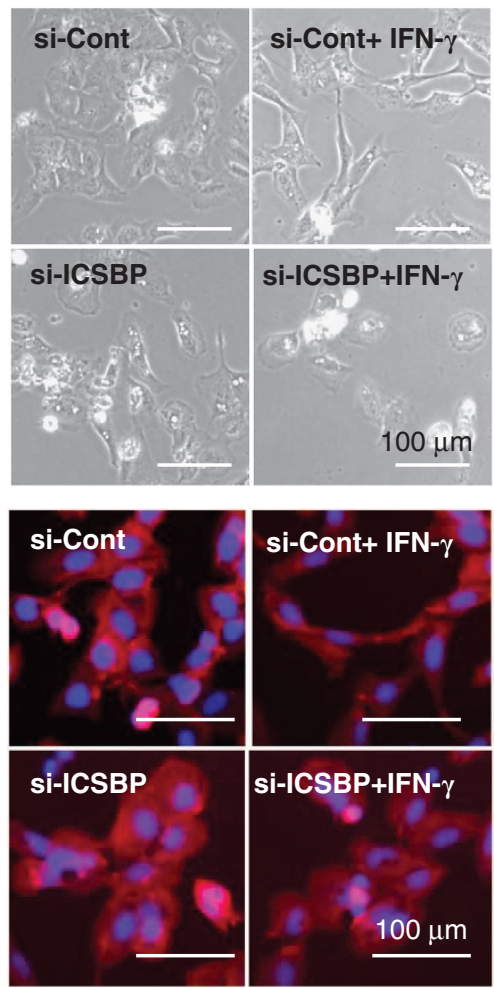
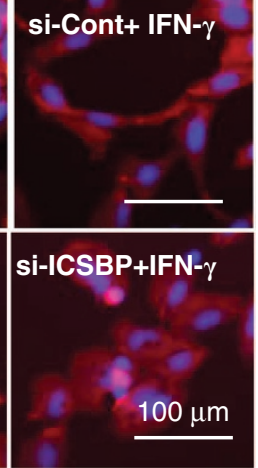

f
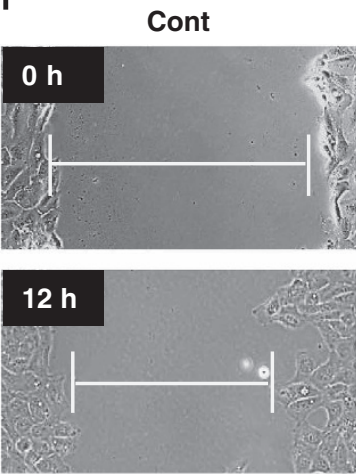

si-ICSBP
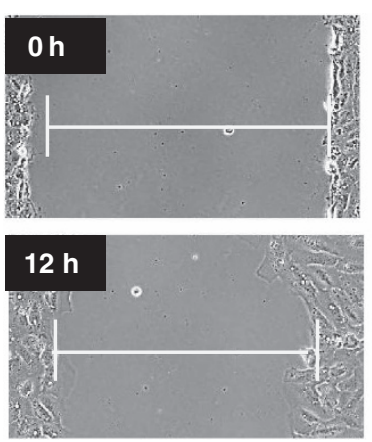

IFN- $\gamma$
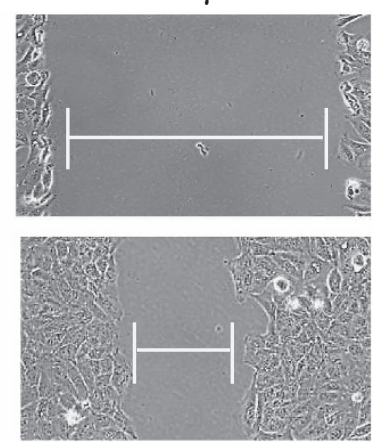

si-ICSBP+IFN- $\gamma$
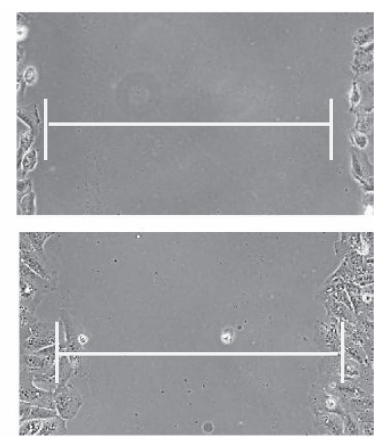

Figure 1 IFN- $\gamma$ induces ICSBP expression and cell morphology changes in U2OS cells. (a) U2OS cells were treated for $24 \mathrm{~h}$ with $0-300 \mathrm{IU} / \mathrm{ml}$ of IFN- $\gamma$. Cell lysates were prepared and immunoblotted with ICSBP, pSTAT1, and $\beta$-actin antibodies. $\beta$-Actin levels were used as a protein loading control. (b) U2OS cells were treated for $24 \mathrm{~h}$ with $300 \mathrm{IU} / \mathrm{ml} \mathrm{IFN}-\gamma$, and phase-contrast images were taken. Scale bars indicate $100 \mu \mathrm{m}$. (c) Cell lysates from panel (b) were analyzed by immunoblotting using anti-ZO-1, antifibronectin, and anti-vimentin antibodies. (d) U2OS cells were transfected with control siRNA (si-Cont) or siRNA specific for ICSBP (si-ICSBP) as described in Materials and Methods. Cells were grown for $24 \mathrm{~h}$ in the absence or presence of IFN- $\gamma(300 \mathrm{U} / \mathrm{ml})$ and were analyzed by immunoblotting using anti-ICSBP, anti-pSTAT1, and anti- $\beta$-actin antibodies. (e) Cells were treated as in panel (d) and stained with DAPI (4,6-diamidino-2-phenylindole) and phalloidine for nucleus and actin, respectively. Cell images were obtained using a phase-contrast confocal microscope. Scale bars indicate $100 \mu \mathrm{m}$. (f) Confluent U2OS cells were grown in six-well plates, and the cell monolayer was scratched with a plastic pipette tip. Cells were then treated without or with IFN- $\gamma$ and cultured for $12 \mathrm{~h}$. Alternatively, U2OS cells were transfected with si-ICSBP for $24 \mathrm{~h}$, and the confluent cells were scratched and treated without (Si-ICSBP) or with IFN- $\gamma($ Si-ICSBP + IFN- $\gamma$ ) for $12 \mathrm{~h}$. Cell images were captured with a Zeiss inverted microscope. Vertical lines mark the wounded margins. Experiments were performed three times with similar results 
a
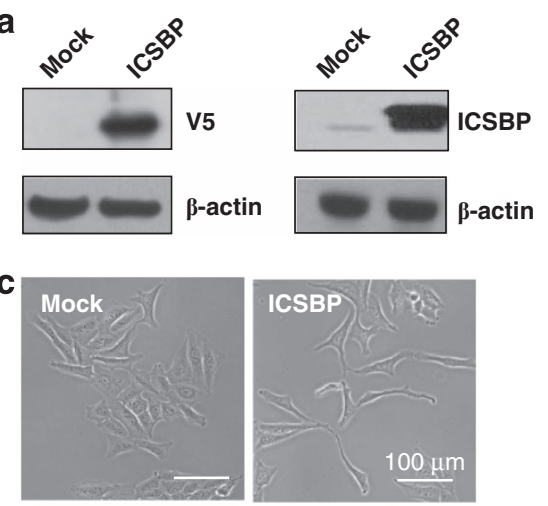

d

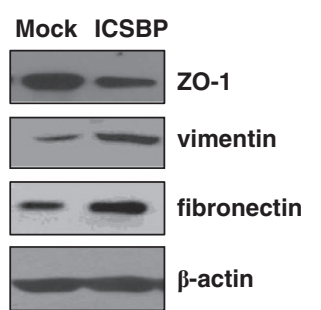

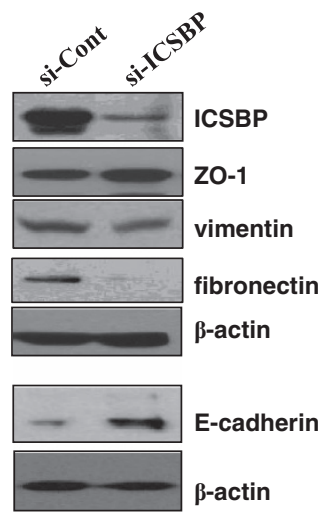

b
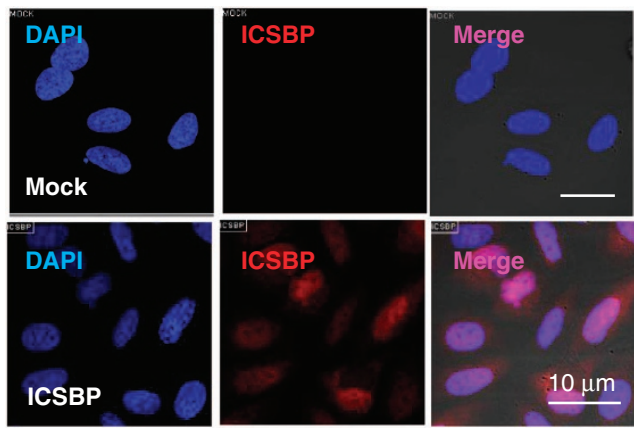

e

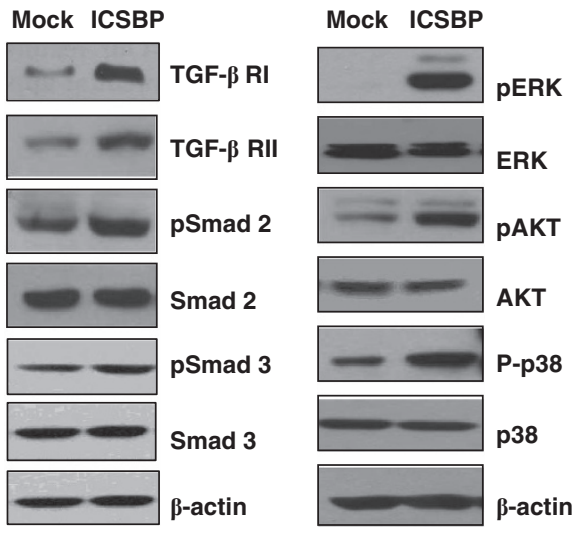

$\mathbf{f}$

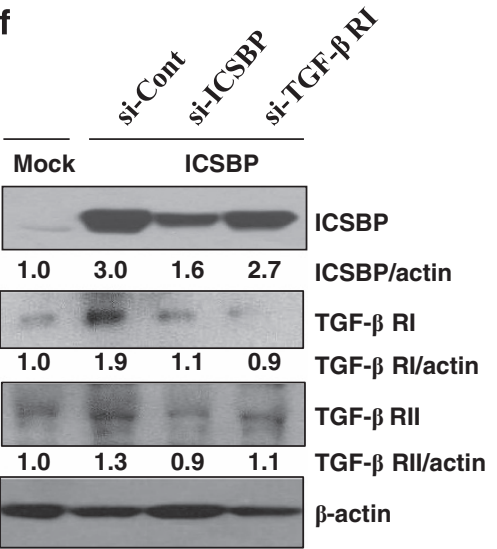

Figure 2 ICSBP overexpression induces EMT-like morphological changes and enhances TGF- $\beta$ receptor expression and signaling in U2OS cells. (a) U2OS cells were transfected with empty vector (Mock) or ICSBP-expressing vector (ICSBP-V5) as described in Materials and Methods. Stable cells were selected with G418 for 4 weeks. Cell lysates were prepared and analyzed by immunoblotting using anti-V5, anti-ICSBP, and anti- $\beta$-actin antibodies. (b) Mock and ICSBP cells were stained with DAPI (4,6diamidino-2-phenylindole) and the anti-ICSBP antibody and analyzed by a confocal microscopy. Scale bar indicates $10 \mu \mathrm{m}$. (c) Representative phase-contrast images of Mock and ICSBP-expressing cells. Scale bar indicates $100 \mu \mathrm{m}$. (d). Mock and ICSBP cells were transfected with si-Cont RNA or si-ICSBP RNA, and cell lysates were analyzed by immunoblotting with the indicated antibodies. (e) Cell lysates from Mock and ICSBP cells were analyzed by immunoblotting using the indicated antibodies. The levels of pSmad2, Smad2, pSmad3, and Smad3 were quantified by a densitometry and normalized to $\beta$-actin levels. When the ratios of pSmad2 to Smad2 and pSmad3 to Smad3 in the Mock cells were set at 1 , those in the ICSBP cells were 1.4 and 1.2, respectively. (f) ICSBP cells were transfected with the siRNAs (si-Cont, si-ICSBP, or si-TGF- $\beta$ RI) for $24 \mathrm{~h}$. Cell lysates were analyzed by immunoblotting using the antibodies against ICSBP, TGF- $\beta$ RI, TGF- $\beta$ RII, and $\beta$-actin. The ratios of ICSBP, TGF- $\beta$ RI, and TGF- $\beta$ RII relative to $\beta$-actin in the Mock cells were set at 1. (g) ICSBP cells were transfected with si-Cont RNA or si-ICSBP RNA for $24 \mathrm{~h}$. Cell lysates were analyzed by immunoblotting using the indicated antibodies. The ratios of pSmad2 to Smad2 and pSmad3 to Smad3 in the ICSBP cells transfected with si-Cont were set at 1. Experiments were performed three times with comparable results

ICSBP acts as a transcriptional regulator of TGF- $\beta$ RI. Next, we tested whether ICSBP expression is associated with TGF- $\beta$ RI expression in patient-derived osteosarcoma tissues. An osteosarcoma tissue microarray obtained from
60 patients were stained for ICSBP and TGF- $\beta$ RI at three different times, yielding very similar staining patterns. A representative picture of ICSBP and TGF- $\beta$ RI staining results with varying intensities (negative to strong) was 
a

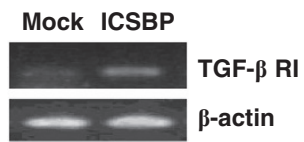

b

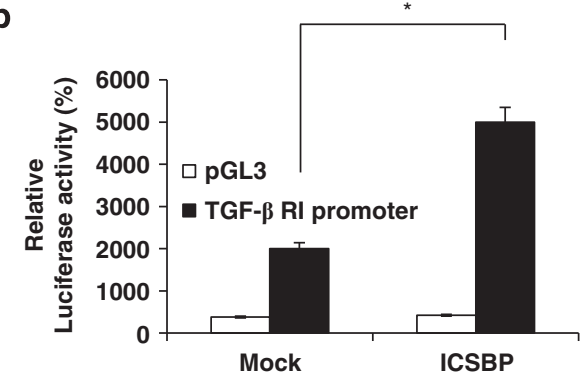

d

\begin{tabular}{|c|c|c|c|c|}
\hline Intensity & Negative & Weak & Intermediate & Strong \\
\hline $\begin{array}{l}\text { ICSBP } \\
(n=54)\end{array}$ & $\begin{array}{c}9 \\
(17 \%)\end{array}$ & $\begin{array}{c}30 \\
(56 \%)\end{array}$ & $\begin{array}{c}12 \\
(22 \%)\end{array}$ & $\begin{array}{c}3 \\
(5 \%)\end{array}$ \\
\hline $\begin{array}{c}\text { TGF- } \beta \text { RI } \\
(n=54)\end{array}$ & $\begin{array}{c}7 \\
(13 \%)\end{array}$ & $\begin{array}{c}20 \\
(37 \%)\end{array}$ & $\begin{array}{c}22 \\
(41 \%)\end{array}$ & $\begin{array}{c}5 \\
(9 \%)\end{array}$ \\
\hline
\end{tabular}

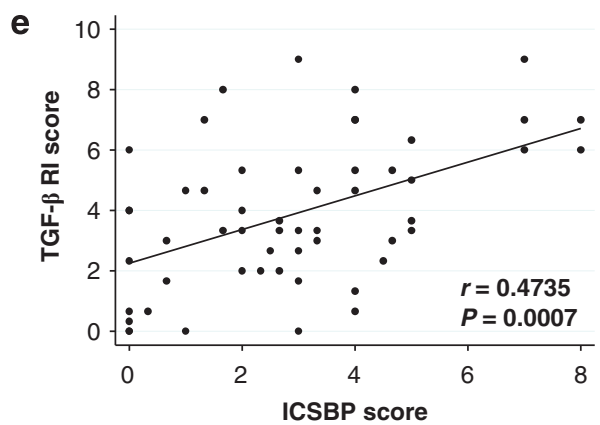

C
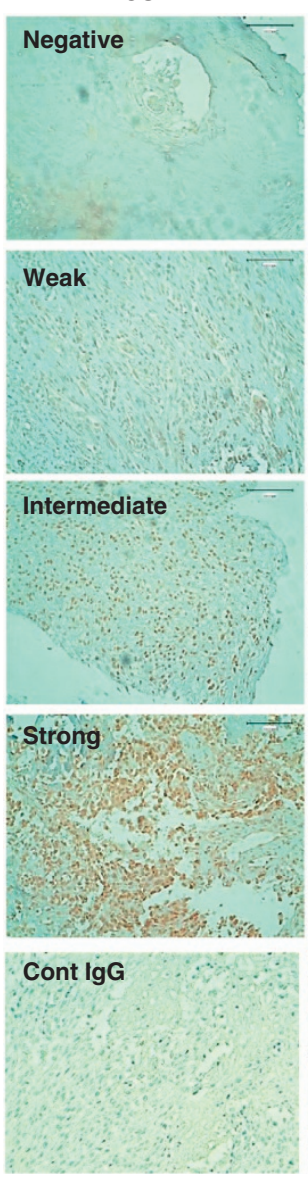

TGF- $\beta$ RI
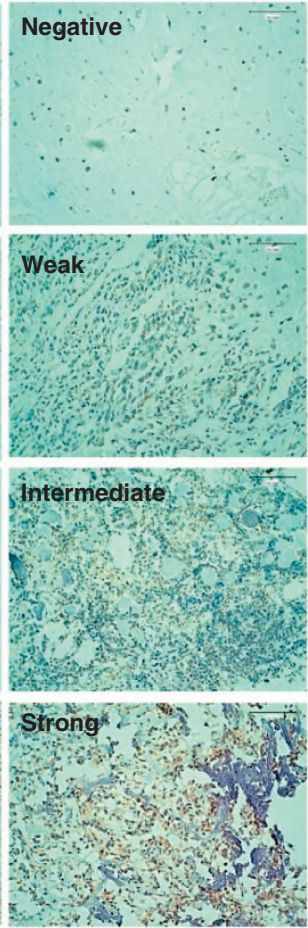

Cont igG

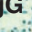

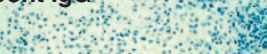
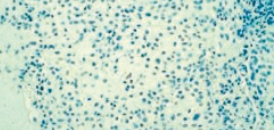

Figure 3 Effect of ICSBP on TGF- $\beta$ receptor expression and their relationship in human osteosarcoma tissues. (a) Total mRNAs from Mock or ICSBP cells were subjected to RT-PCR of TGF- $\beta$ RI. Actin was used as a control. (b) Mock and ICSBP cells were transfected with either control luciferase reporter vectors (pGL3) or TGF- $\beta$ RI promoterluciferase reporter vectors for $24 \mathrm{~h}$. Luciferase activities of Mock and ICSBP cell lysates were measured and normalized by control luciferase activity. Data are presented as averages of triplicate measurements with error bars representing S.Ds. ${ }^{*} P<0.005$ (c) Patient-derived osteosarcoma tissue microarray was examined for ICSBP and TGF- $\beta$ RI expression using immunoperoxidase method. Staining results were graded according to the intensity and proportion of positive cells as described in the Supplementary Materials and Methods. (d) Fifty-four adequate sections of the 60 were classified according to their staining intensities for ICSBP and TGF- $\beta$ RI. (e) Correlation between ICSBP and TGF- $\beta$ RI expression in the tumor tissues from 54 osteosarcoma patients was examined using the Pearson's correlation method $(r=0.4735, P=0.0007)$. Experiments were performed three times with comparable results

depicted (Figure 3c). Fifty-four of the 60 sections with tumor cells were readable, and their distribution according to staining intensities with regard to ICSBP and TGF- $\beta \mathrm{RI}$ are shown in Figure $3 d$. In all, 45/54 (83\%) and 47/54 (87\%) of the sections were positive for ICSBP and TGF- $\beta$ RI expression, respectively. Combined weak and intermediate intensities for ICSBP and TGF- $\beta$ RI each represented $78 \%$ of the 54 sections. In addition, TGF- $\beta$ RI staining scores were significantly related to ICSBP scores $(r=0.4735 ; P=0.0007$; Figure $3 e$ ), suggesting a relation between ICSBP and TGF- $\beta$ $\mathrm{RI}$ expression in vivo.

ICSBP enhances cell adhesion and motility. Because ICSBP expression induced EMT-like morphological changes (Figures 1 and 2), we examined whether ICSBP can affect cell adhesion and motility, which are another important properties of EMT. We found that ICSBP cells adhered to culture plates more quickly and spread out faster than Mock cells (Figure 4a). To compare the adhesiveness between the two cell lines, adherent cells were counted at the indicated times after cell plating. Although the same number of cells was initially plated, more ICSBP cells were attached as compared with Mock cells (Figure 4b). Next, we examined cell movement using a Zeiss Axio observer live cell station. Mock cells remained at their initial marking spots for up to $1 \mathrm{~h}$, but ICSBP cells moved around and migrated out of their initial spots as early as $30 \mathrm{~min}$ after plating (Figure 4c). In addition, wound-closure assays revealed that ICSBP cells filled the wounded area faster than Mock cells (Figure 4d). Because ICSBP enhanced TGF- $\beta$ RI expression and signaling (Figure 2), we explored whether the increased motility of ICSBP cells is mediated by TGF- $\beta$ receptor 
a

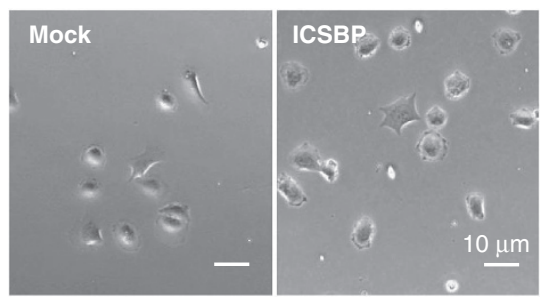

b

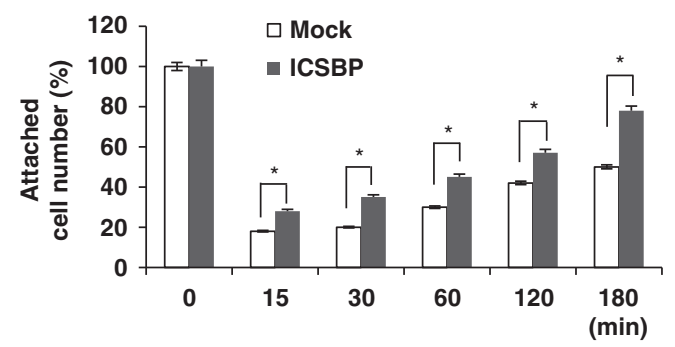

C
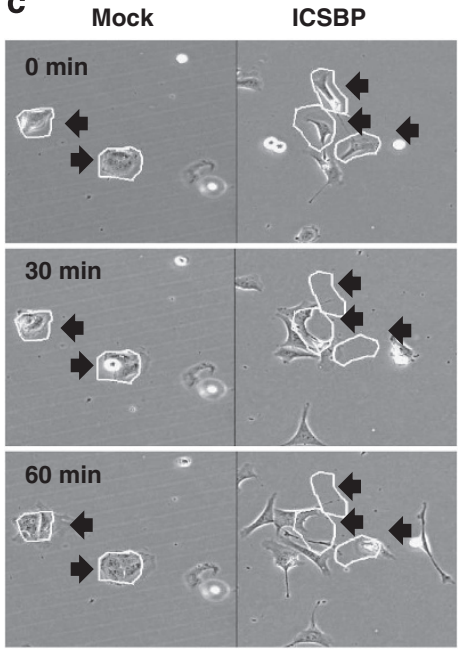

d
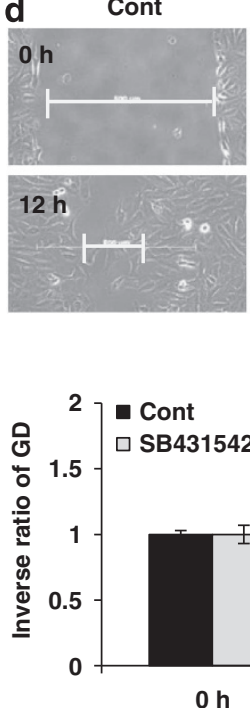

SB431542
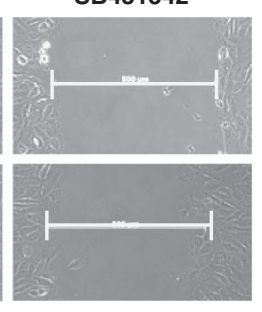

e si-Cont

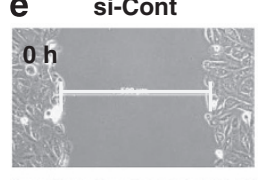

si-ICSBP
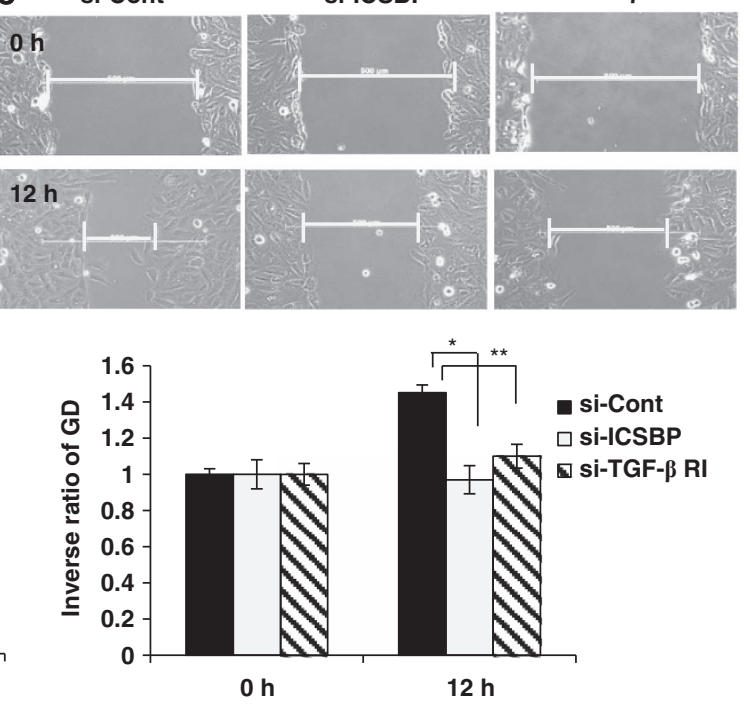

Figure 4 ICSBP enhances cell adhesion and motility. (a) Mock and ICSBP cells were seeded onto culture plates and incubated for $3 \mathrm{~h}$. Unattached cells were removed by washing, and phase-contrast images of attached cells were obtained. (b) An equal number of cells were cultured as in panel (a), and attached cells were trypsinized and counted after Trypan blue staining at the indicated times. The initial number of cells for plating was regarded as 100\% ( $0 \mathrm{~min}$ ). Data are presented as averages of triplicate measurements with error bars representing S.Ds. ${ }^{*} P<0.01$. (c) Mock and ICSBP-expressing cells were grown for $24 \mathrm{~h}$ in six-well plates and time-lapse images of cells were acquired using the Zeiss Axio observer live cell station every minute for $1 \mathrm{~h}$ ( $\times 40$ magnifications). (d) Confluent layers of Mock and ICSBP cells grown in six-well plates were scratched with plastic pipette tips. Cells were then cultured for an additional $12 \mathrm{~h}$, and images were captured with an inverted microscope. In addition, ICSBP cells were treated with $20 \mu \mathrm{M} \mathrm{SB} 431542$ for $3 \mathrm{~h}$ before scratching. Vertical lines mark the wounded margins. Degree of cell motility was expressed as an inverse ratio of gap distance (GD) at $12 \mathrm{~h}$ relative to that at $0 \mathrm{~h}$. $P<0.01$. Value was expressed as mean \pm S.D. for three measurements. (e) ICSBP cells were transfected with si-Cont, si-ICSBP, or si-TGF- $\beta$ RI for $24 \mathrm{~h}$ before scratching. Images were captured with an inverted microscope. Degree of cell motility was analyzed as described in panel (d). ${ }^{*} P($ si-Cont versus si-ICSBP) $<0.01$, ${ }^{\star *} P$ (si-Cont versus si-TGF- $\beta$ RI) $<0.01$. Similar results were observed in three independent experiments. Value was expressed as mean \pm S.D. for three measurements

activation. As expected, the wound-healing ability of ICSBP cells was blocked by the TGF- $\beta$ receptor inhibitor, SB431542 (Figure 4d). These data suggest that TGF- $\beta$ receptor activation is important for enhanced wound healing in ICSBP cells. Furthermore, knock-down of either ICSBP or TGF- $\beta$ RI inhibited wound healing, whereas control siRNA did not (Figure $4 \mathrm{e}$ ). All these data indicate that ICSBP regulates cell adhesion and motility mediated by TGF- $\beta$ RI.

ICSBP upregulates various E-cadherin repressors and Snail enhances ELP, cell motility, and invasion. Snail, Slug, and Twist are well-known transcriptional repressors of
E-cadherin. ${ }^{6}$ TGF- $\beta$ signaling induces EMT and metastasis by regulating these transcription factors. ${ }^{3}$ To investigate the molecular mechanisms involved in ICSBP-mediated ELP and cell motility, we examined the expression levels of Snail, Slug, and Twist and found that both mRNA and protein expression levels of these molecules were upregulated in ICSBP cells (Supplementary Figure S1, Figure 5a). siRNA knockdown of ICSBP decreased the levels of Snail, Slug, and Twist, and the downregulation of Snail was most remarkable (Figure 5b). si-TGF- $\beta$ RI did not efficiently knock down Slug and Twist molecules. However, Snail expression was decreased by si-TGF- $\beta$ RI although much less than by 
a

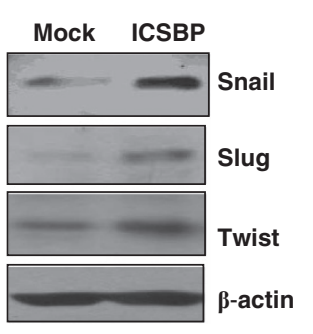

b

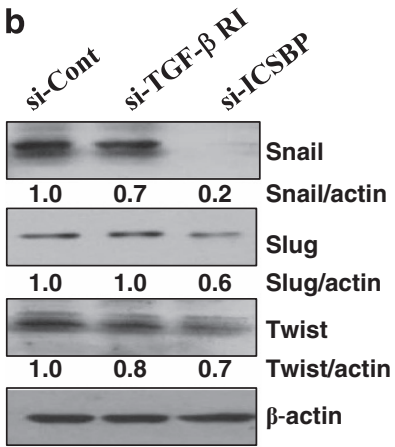

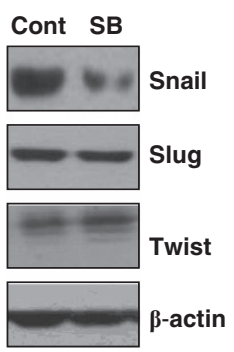

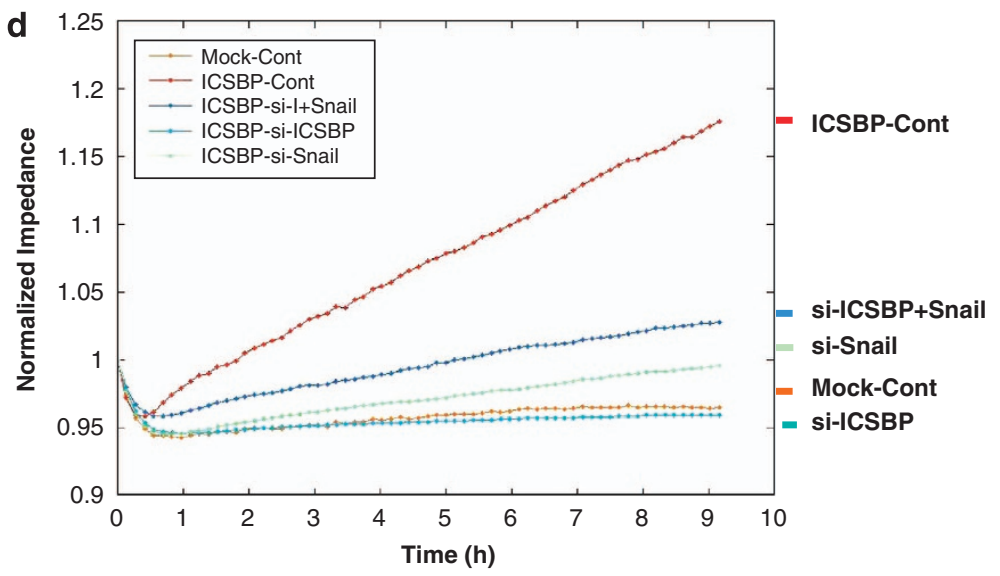

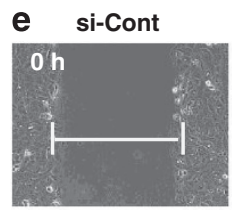

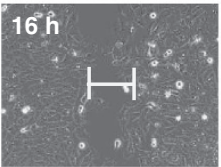

si-Snail
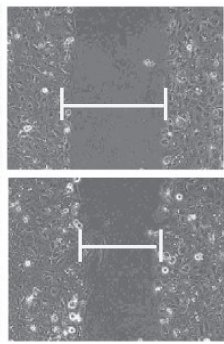

1.8 si-Control

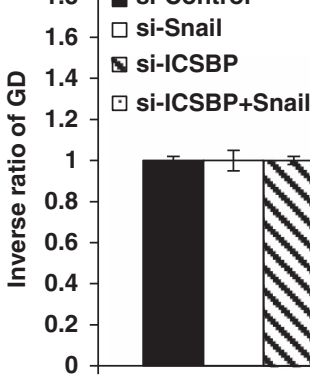

$\mathbf{O h}$

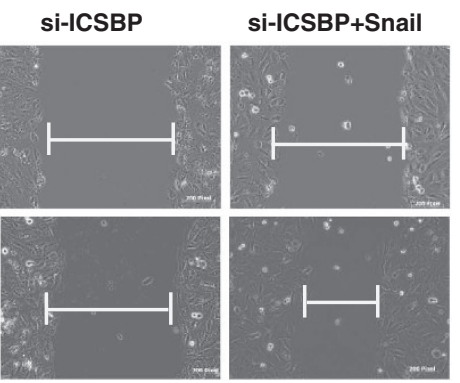

f

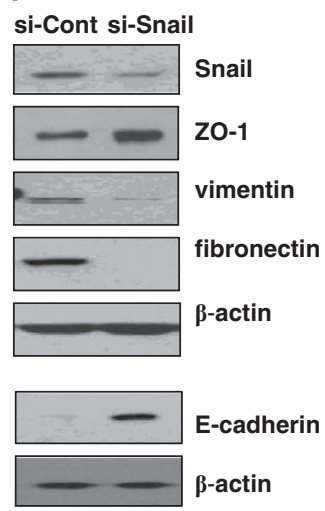

Figure 5 ICSBP upregulates various E-cadherin repressors, and Snail is important for cell motility. (a) Cellular protein from Mock and ICSBP cells were analyzed by immunoblotting with anti-Snail, anti-Slug, anti-Twist, and anti- $\beta$-actin antibodies. (b) ICSBP cells were transfected for $24 \mathrm{~h}$ with si-Cont, si-TGF- $\beta$ RI, or si-ICSBP. Cell lysates were prepared for immunoblot analysis with the indicated antibodies. The levels Snail, Slug, and Twist were quantified by densitometry and normalized to $\beta$-actin levels. The ratios of Snail, Slug, and Twist to total $\beta$-actin in the ICSBP cells transfected with si-Cont were set at 1. (c) ICSBP cells were treated with DMSO (control) or $20 \mu \mathrm{M}$ SB431542 and cell lysates were analyzed by immunoblotting as indicated. (d) ICSBP cells were transfected for $24 \mathrm{~h}$ with si-Cont (ICSBP-Cont), si-ICSBP, si-Snail, or si-ICSBP plus Snail (si-ICSBP + Snail). An equal number of cells $\left(2.0 \times 10^{4}\right.$ cells/well) were plated, and cell attachment was analyzed using the ECIS system as described in Materials and Methods. Impedance was monitored immediately after seeding. Mock cells transfected with si-Cont (Mock-Cont) were used as a control. (e) ICSBP cells were transfected for $24 \mathrm{~h}$ with si-Cont, si-Snail, si-ICSBP, or si-ICSBP plus Snail expression vector (si-ICSBP + Snail). The confluent cell monolayer was scratched with sterile pipette tips, and wound healing was monitored for $12 \mathrm{~h}$ using a live cell imager. Degree of cell motility was expressed as an inverse ratio of gap distance (GD) at $16 \mathrm{~h}$ relative to that at $0 \mathrm{~h}$. ${ }^{*} P<0.05$ (si-Control versus si-ICSBP), ${ }^{* *} P<0.05$ (si-ICSBP versus si-ICSBP + Snail). Similar results were observed in three independent experiments. Value was expressed as mean \pm S.D. for three measurements. (f) ICSBP cells were transfected for $24 \mathrm{~h}$ with si-Cont or si-Snail. Total protein was analyzed by immunoblotting as indicated 
si-ICSBP (Figure 5b), suggesting the presence of additional pathways besides TGF- $\beta$ receptor signal, with regard to the regulation of Snail by ICSBP (Supplementary Figure S8). Snail expression was suppressed appreciably by SB431542, an inhibitor of the TGF- $\beta$ receptor (Figure $5 c$ ). Therefore, we tested whether Snail affects ICSBP-mediated cell attachment and spreading using electrical cell-substrate impedance sensing (ECIS). Cell attachment and spreading can be monitored in real time with the ECIS system by measuring changes in impedance evoked by cell attachment and spreading. Impedance increases as electrodes are covered with cells. Impedance was increased in ICSBP-Cont cells (ICSBP cells transfected with si-control) but remained low in si-ICSBP cells (ICSBP cells transfected with si-ICSBP) (Figure $5 d$ ). Relatively low impedance was also recorded when Snail was knocked down in the ICSBP cells (si-Snail). However, co-transfection of a Snail expression vector and si-ICSBP (si-ICSBP + Snail) resulted in increased impedance. These data indicate that cell attachment is enhanced in ICSBP cells and further support the results shown in Figures $4 \mathrm{a}$ and $\mathrm{b}$. These data also suggest that Snail is important for the adhesiveness of the ICSBP cells.

To further examine whether Snail is involved in ICSBPinduced cell motility, we reduced Snail expression using si-Snail RNA and performed wound-healing assays. Woundhealing ability of ICSBP cells was decreased when Snail expression was knocked down. Co-transfection of Snail considerably recovered wound-healing ability of si-ICSBPtransfected cells (Figure 5e). Reduction of Snail expression resulted in an increase in ZO-1, E-cadherin and a decrease in vimentin and fibronectin levels, indicating that Snail regulates EMT molecules in ICSBP cells (Figure 5f). Next, we performed migration and invasion assays using transwell plates coated with Matrigel. ICSBP cells invaded through the Matrigel and migrated toward the lower wells. However, Mock cells showed minimal invasion and migration capabilities (Figure 6a). ICSBP cell invasion was inhibited by knockdown of ICSBP, but co-transfection with Snail could partially recover the migration and invasion. We further evaluated whether ICSBP cells migrate through endothelial cells using the ECIS system. Impedance is decreased when the endothelial cell monolayer is retracted by trans-endothelial migration of invading cells. As shown in Figure $6 \mathrm{~b}$, in human umbilical vein endothelial cell (HUVEC)-only wells, high resistance was maintained. However, upon the addition of ICSBP cells to the HUVEC monolayer, impedance decreased dramatically, indicating that ICSBP cells effectively invade the HUVEC monolayer. The lowered impedance was recovered with ICSBP knockdown (si-ICSBP), resulting in similar impedance to that of Mock cells. When Snail was transfected along with si-ICSBP (si-ICSBP + Snail), impedence declined again, indicating that Snail causes cell invasion even when ICSBP is knocked down. Next, we examined the effects of ICSBP expression in other human osteoasarcoma cell lines, Saos-2 and 143B. Stable expression of ICSBP induced EMT-like morphological changes (Figure 6c), and Snail expression was increased by ICSBP expression (Figure 6d) in both the cell lines. EMT-like morphology induced by ICSBP was attenuated by ICSBP knockdown, which was reversed by Snail expression in ICSBP overexpressing 143B (143B-ICSBP) cells (Figure 6e). As for invasiveness, 143B-ICSBP cells showed better invasion ability than 143B-Mock cells. 143BICSBP cell invasion was blocked by si-ICSBP, which was partially recovered by Snail expression. Taken together, these results indicate that ICSBP induces ELP and increases invasiveness, which are mediated, at least in part, by Snail.

\section{Discussion}

ICSBP, also known as IRF8, is a transcriptional regulator that is known to be a tumor suppressor in hematopoietic tumors, including myeloid leukemia. ${ }^{10}$ However, we previously have demonstrated that ICSBP enhances cell proliferation via TGF- $\beta$ pathway activation in HL-60 and Jurkat leukemic cells. ${ }^{13}$ These data indicate that ICSBP might have a tumorpromoting ability, in addition to its tumor-suppressive function, depending on the cell type or cellular context. In this study, we propose a new role for ICSBP in the regulation of metastatic properties by demonstrating that ICSBP induced ELP and enhanced cell motility and invasion in U2OS cells through activation of TGF- $\beta$ and Snail signaling. We also illustrated a positive correlation between ICSBP and TGF- $\beta$ RI expression as well as TGF- $\beta$ RI and Snail (Supplementary Figure S7C) in human osteosarcoma tissues.

Inflammatory cytokines, including IL- $1 \beta$, TNF- $\alpha$, and IFN- $\gamma$, are known to enhance TGF- $\beta$-induced EMT in A549 lung carcinoma cell line. ${ }^{16}$ The combination of cytokines upregulates TGF- $\beta$ RI, and siRNA suppression of TGF- $\beta$ RI, Smad2, or Smad3 blocks the synergistic effect on EMT. However, molecular mechanisms underlying TGF- $\beta$ receptor upregulation by this cytokine mixture have not been addressed. In our study, we observed that IFN- $\gamma$ induced ELP in U2OS cells. The observed ELP was inhibited by knocking down ICSBP, indicating that ICSBP is responsible for IFN- $\gamma$-induced ELP induction (Figure 1). We also found that the addition of IFN- $\gamma$ enhanced TGF- $\beta$ RI expression in U2OS cells and ICSBP knockdown inhibited IFN- $\gamma$-induced TGF- $\beta$ RI expression in U2OS cells (Supplementary Figure S2a), indicating that ICSBP has a role in ELP regulation through TGF- $\beta$ RI expression.

Although not well studied, ICSBP appears to have a role in cell migration. Bone marrow-derived dendritic cells from ICSBP $^{-1-}$ mice show a defect in their migratory response. ${ }^{17}$ In addition, in bone marrow-derived macrophages from $\mathrm{ICSBP}^{-1-}$ mice, disabled-2 protein (Dab-2) is upregulated and induces macrophage adhesion and spreading. ${ }^{14}$ These studies suggest that ICSBP has a critical role in regulating dendritic cell migration and macrophage adhesion. In agreement with these results, our study illustrated that ICSBP enhanced cell adhesion, migration, and invasion in U2OS cells. Compared with Mock cells, there was an approximate $10 \%$ increase in cell growth in ICSBP cells after $24 \mathrm{~h}$ (Supplementary Figure S3a). Therefore, we could rule out the possibility that ICSBP-enhanced cell motility and invasion were caused by increased cell proliferation, because enhanced motility and invasion were observed much earlier than $24 \mathrm{~h}$. In addition, it seems unlikely that $\mathrm{TGF}-\beta$ receptor activation was mediated by TGF- $\beta$, because secreted amounts of TGF- $\beta 1$ were comparable between the 
a

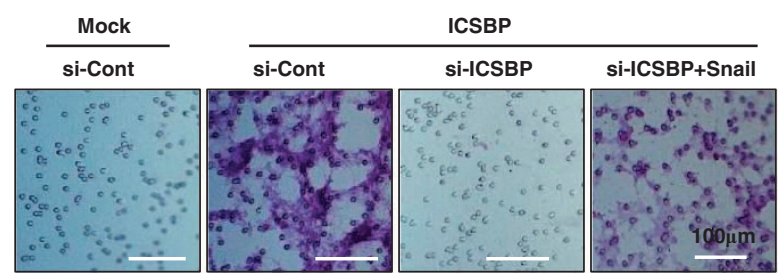

b
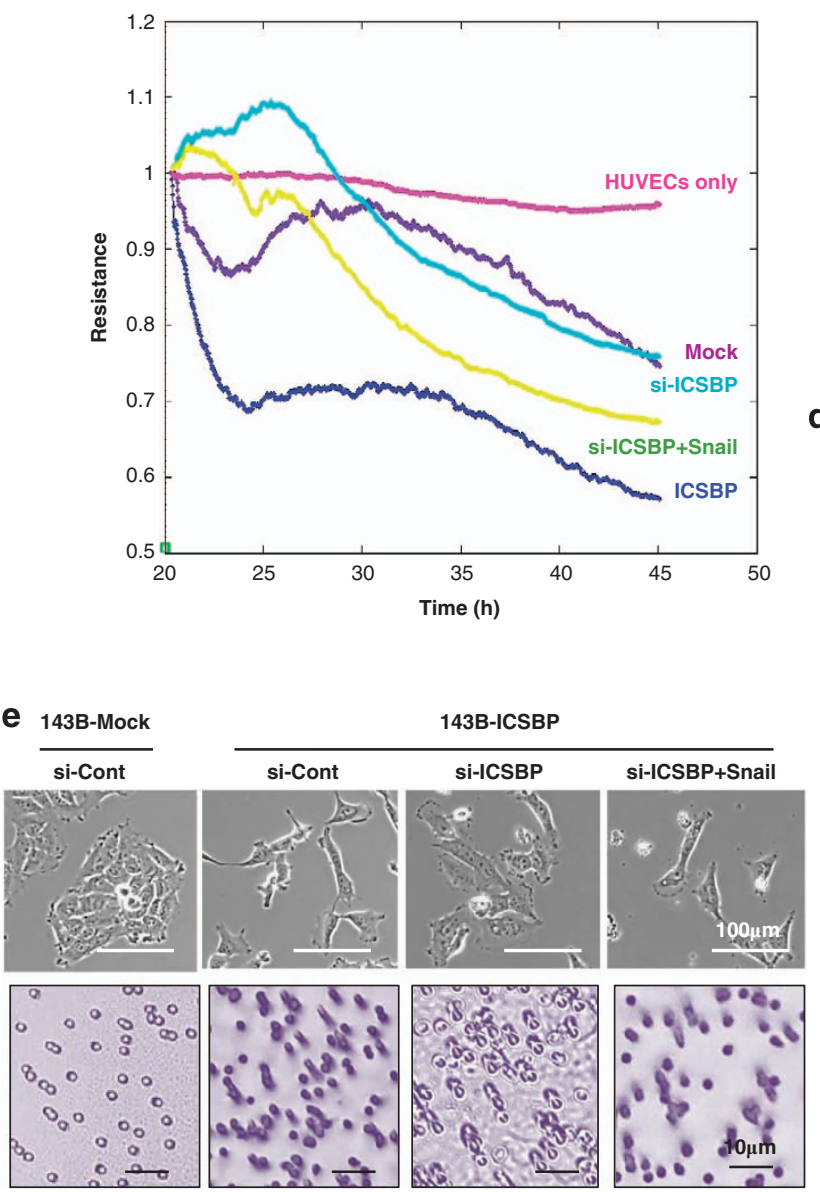

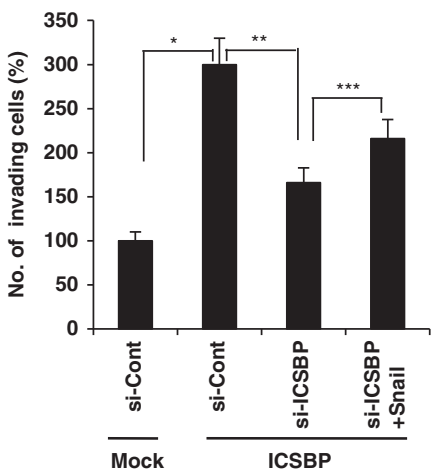

C
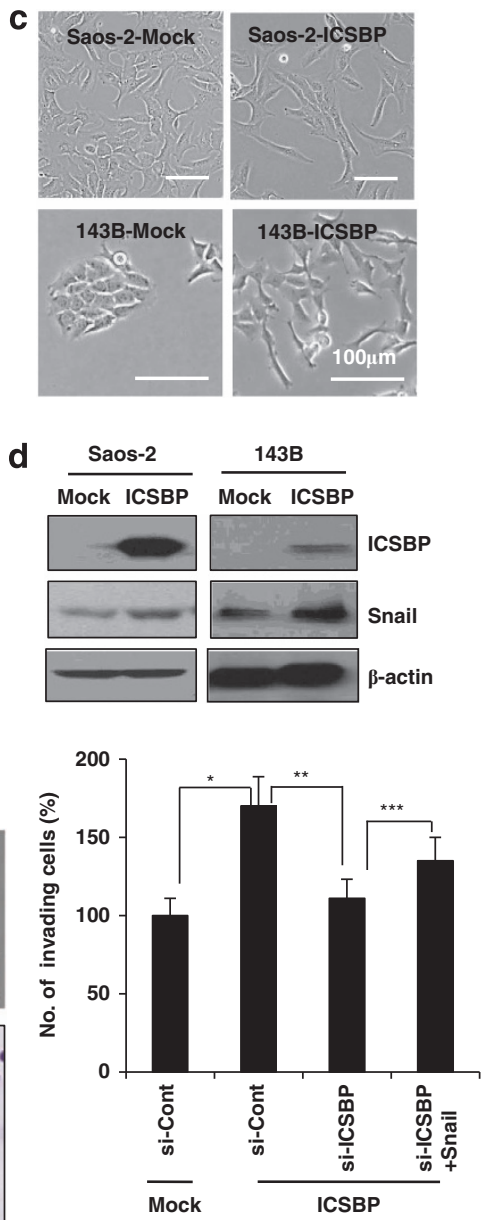

Figure 6 ICSBP enhances cell motility and invasion via Snail expression. (a) ICSBP cells were transfected for $24 \mathrm{~h}$ with si-Cont, si-ICSBP, or si-ICSBP plus Snail expression vector (Si-ICSBP + Snail). Cells were seeded into the upper wells of trans-well chambers coated with Matrigel. After $24 \mathrm{~h}$, cells remaining in the upper chamber were removed and those that invaded the lower chamber were stained with crystal violet. Images were taken at $\times 20$ magnifications. Mock cells were used as a control. ${ }^{*} P<0.05$ (Mock si-Cont versus ICSBP si-Cont), ${ }^{* \star} P<0.05$ (ICSBP si-Cont versus si-ICSBP), ${ }^{* \star} P<0.05$ (si-ICSBP versus si-ICSBP + Snail). Value was expressed as mean \pm S.D. for three measurements. (b) Changes in resistance evoked by invasion of Mock, ICSBP cells, or ICSBP cells transfected with si-ICSBP or si-ICSBP plus Snail (siICSBP + Snail) into the confluent layer of HUVECs. Changes in resistance were monitored for $45 \mathrm{~h}$. (c) Representative phase-contrast images were obtained from Mock- or ICSBP-expressing Soas-2 and 143B cell lines. (d) Cell lysates from panel (c) were analyzed by immunoblotting using the indicated antibodies. (e) 143B-Mock and 143BICSBP cells were transfected with si-Cont, si-ICSBP, or si-ICSBP plus Snail (si-ICSBP + Snail) for $24 \mathrm{~h}$, and phase-contrast images were taken (upper panel). Alternatively, the cells treated as above were subjected to Matrigel invasion assay as described in panel (a) (lower panel). ${ }^{*} P<0.05$ (Mock si-Cont versus ICSBP si-Cont), ${ }^{\star \star} P<0.05$ (si-Cont versus si-ICSBP), ${ }^{* *} P<0.05$ (si-ICSBP versus si-ICSBP + Snail). Similar results were observed in three independent experiments. Value was expressed as mean \pm S.D. for three measurements

Mock and ICSBP cells (Supplementary Figure S3b). Therefore, it appears that upregulated TGF- $\beta$ receptor is sufficient to activate its pathway independent of TGF- $\beta$ stimulation. ${ }^{18}$
EMT is a critical process for cancer metastasis. ${ }^{3}$ TGF- $\beta$ has a central role in EMT initiation and cancer metastasis. ${ }^{19}$ TGF- $\beta$ induces EMT through induction of transcription factors, such 
as Snail, Slug, Zeb, and Twist, that downregulate epithelial and upregulate mesenchymal cell markers. ${ }^{20-23}$ In the present study, we observed that ICSBP-induced ELP involves upregulation of Snail, Slug, and Twist (Supplementary Figure S1, Figure 5). Of these, Snail was highly upregulated by ICSBP and was downregulated by either ICSBP knockdown or the addition of a TGF- $\beta$ receptor inhibitor. Consistent with these findings, Snail knockdown reduced wound healing in the ICSBP cells (Figure 5e). In addition, knockdown of Snail increased ZO-1 and E-cadherin and decreased vimentin and fibronectin (Figure 5f). These results indicate that ICSBP induces ELP and enhances cell motility through TGF- $\beta$ and Snail pathways. In support of our results, a recent report demonstrated that Snail knockdown reverts TGF- $\beta$-induced EMT and cell migration in retinal pigment epithelial cells. ${ }^{24}$ In addition to promoting cell motility, ICSBP and Snail increased the invasiveness of U2OS cells through an endothelial cell layer (Figure 6). However, Snail introduction did not fully revert decreased wound healing and invasiveness resulting from ICSBP knockdown in the ICSBP cells (Figure 5e, Figure 6a). In addition, Snail expression was weakly associated with ICSBP expression in osteosarcoma tissues ( $r=0.2319 ; P=0.0948$; Supplementary Figure S7B). These findings might be explained by the presence of additional ICSBP-regulated molecules other than Snail, working on ELP, such as Slug and Twist (Supplementary Figure S8). Recent clinicopathological data revealed that Twist and E-cadherin are expressed in the tissues of osteosarcoma patients. ${ }^{25}$ Twist was expressed significantly more and E-cadherin significantly less in osteosarcoma patients with metastasis, indicating that expression of both molecules might be related to the prediction of metastasis potency and poor prognosis for patients with osteosarcoma. ICSBP-induced Snail expression, ELP, and invasion were not limited to U2OS cells, because these phenomena were also observed in other osteosarcoma cell lines, Saos-2, and 143B cells (Figure 6). Because we observed ICSBP-induced EMT-like morphological change and increased invasiveness in non-epithelial osteosarcoma cells, it will be interesting to explore whether this occurs in other tumor cells of mesenchymal origin.

Similar to our previous findings in $\mathrm{HL} 60$ cells, ${ }^{13}$ in U2OS cells, ICSBP expression activates TGF- $\beta$ receptor signaling, including activation of Smad pathways and non-Smad pathways, such as ERK1/2, phosphoinositide 3 kinase (PI3K)AKT, and p38 mitogen-activated protein kinase (Figure 2), that are involved in cell motility. Increased cell motility induced by ICSBP was demonstrated in wound-healing assay, where the ICSBP cells filled most of the gap in $12 \mathrm{~h}$ while Mock cells did only a small portion of the gap (Supplementary Figure S4). To investigate which pathway is critical for ICSBP-induced cell motility, cells were treated with LY294002, U0126, and SB431542, which are inhibitors for PI3K, mitogen-activated protein kinase kinase, and TGF- $\beta$ RI, respectively. SB431542 effectively blocked wound healing in ICSBP cells while blocking effect of LY294002 or U0126 was less pronounced (Supplementary Figure S4). These results indicate that TGF- $\beta$ receptor is critically involved in ICSBP-induced cell motility, and PI3K-AKT and ERK also participate in the process.

ICSBP is known to be a tumor suppressor, and its expression is reduced in multiple hematopoietic ${ }^{26}$ and non-hematopoietic tumors. ${ }^{12}$ Ectopic expression of ICSBP in silenced tumor cells strongly inhibited their clonogenicity, suggesting that ICSBP is a functional tumor-suppressor gene. ${ }^{12}$ In addition, ICSBP expression has been associated with increased cell death. ${ }^{11}$ However, ICSBP expression did not cause cell death (data not shown) but increased cell proliferation in U2OS osteosarcoma cells (Supplementary Figure S3A). Surprisingly, ICSBP expression induced notable changes in U2OS cell morphology resembling EMT. Therefore, we focused on the role of ICSBP in the regulation of ELP and cell motility.

Lack of ICSBP transcripts and epigenetic inactivation of ICSBP have been reported in hematopoietic and nonhematopoietic tumors, respectively. ${ }^{26,12}$ Promoter methylation of ICSBP was detected in $100 \%$ of nasopharyngeal, $88 \%$ of esophageal, and $18-78 \%$ of other multiple carcinoma cell lines. However, lack of ICSBP transcripts was neither demonstrated in $21-34 \%$ of myeloid leukemia, $100 \%$ of chronic lymphocytic leukemia, and $64 \%$ of acute lymphoblastic leukemia patient samples ${ }^{26}$ nor in $82 \%$ of gastric and almost $100 \%$ of hepatocellular carcinoma cell lines. ${ }^{12} \mathrm{We}$ found that ICSBP was expressed in $83 \%$ of our human osteosarcoma tissues (Figure $3 d$ ). These results suggest that at least in osteosarcoma ICSBP is not a tumor suppressor.

In conclusion, our data suggest a model in which ICSBP augments TGF- $\beta$ signaling and the expression of EMT-related transcription factors, including Snail, causing changes in ZO-1, fibronectin, and vimentin levels. These changes result in ELP, increased cell motility, and invasion (Supplementary Figure S8). Although ICSBP is largely known as a tumor suppressor, its expression could confer properties related to metastasis, including an EMT-like phenotype and increase in adhesiveness, motility, and invasiveness, through an activation of TGF- $\beta$ and Snail signaling.

\begin{abstract}
Materials and Methods
Cell culture, antibodies, and reagents. The U2OS, Saos-2 and 143B human osteosarcoma cell lines were obtained from American Type Culture Collection (Rockville, MD, USA) and maintained in RPMI 1640 media (Gibco Life Technologies, Grand Island, NY, USA) supplemented with $10 \%$ fetal bovine serum (FBS). HUVECs were purchased from Invitrogen (Carlsbad, CA, USA) and maintained in Medium 200 from Gibco Life Technologies supplemented with low serum growth supplement. The antibodies and reagents used are listed in the Supplementary Table S1 and Supplementary Materials and Methods. Human Snail expression vectors were purchased from Addgene (Cambridge, MA, USA).
\end{abstract}

Establishment of ICSBP-overexpressing osteosarcoma cells. Human ICSBP cDNA (clone MGC: 161525) was amplified by PCR using the primers listed in Supplementary Table S2. Preparation and transfection of ICSBP constructs into osteosarcoma cells are described in the Supplementary Materials and Methods.

RT-PCR. Total RNA was extracted from U2OS cells using Trizol reagent (Invitrogen) according to the manufacturer's instructions. CDNA was synthesized using the Maximum RT preMix Kit (iNtRON Biotechnology, Seoul, Korea). Each reaction was performed in a thermal cycler for $60 \mathrm{~min}$ at $45^{\circ} \mathrm{C}$. Further PCR procedure is detailed in the Supplementary Materials and Methods.

Reporter assay. TGF- $\beta$ RI promoter activity of Mock- or ICSBP-transfected U2OS cells was analyzed using a luciferase reporter system as described in the Supplementary Materials and Methods.

Immunohistochemical staining for osteosarcoma tissue microarray. Osteosarcoma tissue arrays were obtained from Superbiochips Laboratories (Seoul, Korea) that has been described previously. ${ }^{27}$ Each array contained 
60 sections obtained from 60 patients by biopsy or surgical resection. Tissue microarray was stained using an immunoperoxidase detection technique and scored as described in the Supplementary Materials and Methods.

Cell attachment assays. Cell attachment assays were performed using ECIS. ECIS (Applied Biophysics, Troy, NY, USA) is a non-invasive means of measuring electrical resistance across a cultured cell monolayer in real time. It has been used for continuous measurement of cell micro-motion, attachment, spreading, and growth. ${ }^{28}$ ICSBP cells were plated at $2.0 \times 10^{4} / 100 \mu /$ well in a 96-well plate that had gold-film electrodes at the bottom and incubated in the humidified incubator $\left(37^{\circ} \mathrm{C}, 5 \% \mathrm{CO}_{2}\right)$. Impedance is increased when the surface coverage of electrodes increases owing to cell attachment and spreading. Impedance was monitored immediately after seeding. Cell attachment was measured at $4 \mathrm{kHz}$ frequency with $300-\mathrm{s}$ intervals for $8 \mathrm{~h}$.

Cell adhesion and invasion assays using ECIS. For cell adhesion assay, $2.0 \times 10^{4}$ cells/well were plated, and impedance change was monitored immediately after seeding. For invasion assay, HUVECs were plated $\left(5.0 \times 10^{4}\right.$ cells/ well), and impedance was measured. When impedance reached a plateau, HUVECs were challenged with either U2OS Mock-transfectants or ICSBP-transfectants $\left(4.0 \times 10^{4} \mathrm{cell} s\right)$ in fresh HUVEC media, and the challenged endothelial cell layer impedance was monitored for $24 \mathrm{~h}$. Triplicate wells were used for each experiment.

Immunoblot analyses. Total cellular proteins were fractionated by $10 \%$ sodium dodecyl sulfate-polyacrylamide gel electrophoresis and transferred to polyvinylidene fluoride membranes. After incubation with primary followed by secondary antibody, transferred proteins were visualized utilizing enhanced chemiluminescence system. The details of procedure are described in the Supplementary Materials and Methods.

RNA interference. siRNAs specific for human ICSBP, TGF- $\beta$ RI, or Snail were purchased from Dharmacon (Lafayette, CO, USA). U2OS Mock or ICSBP stable transfectants were transiently transfected with ICSBP-, TGF- $\beta$ RI-, or Snail-specific siRNAs using Lipofectamine 2000 (Invitrogen) as described by the manufacturer. ICSBP cells transfected with pooled non-specific siRNA duplexes $(100 \mathrm{nM}$; Dharmacon) were used as a control. The cells were analyzed $24 \mathrm{~h}$ posttransfection.

Immunofluorescence and confocal microscopy imaging. Localization of ICSBP expression was determined by obtaining merged images of ICSBP-stained cells with those of DAPI- or phalloidine-Texas red-stained cells as described in the Supplementary Materials and Methods.

Live cell imaging. Live cell imaging of Mock or ICSBP cells were performed using a Zeiss inverted microscope (Carl Zeiss Microscopy, Gottingen, Germany). The cells were plated in a six-well plate and incubated for $24 \mathrm{~h}$ at $37^{\circ} \mathrm{C}$ with $\mathrm{CO}_{2}$ supply. The cell image was traced immediately after plating with a cameraequipped microscope (Carl Zeiss Microscopy).

Wound-healing assay. Mock and ICSBP cells were plated in a six-well culture plate. Cell monolayers were wounded by scratching with sterile micropipette tips, and images were captured using a phase-contrast microscopy immediately $(0 \mathrm{~h})$ and $12 \mathrm{~h}$ after wounding. Gap distance was defined as an average value of measured distances between wounded margins at three randomly chosen points.

Transwell migration assays. Cells were plated at $2.0 \times 10^{4} / 100 \mu /$ well in 48-transwell plates (Corning, New York, NY, USA). The upper chamber was covered with Matrigel (1:3 dilution in RPMI media; BD, San Jose, CA, USA) and the lower chamber contained media supplemented with 20\% FBS. After incubation for $24 \mathrm{~h}$, the cells on the upper side of membrane were removed and those that adhered to the underside of membrane were fixed with ice-cold methanol and stained with crystal violet (Sigma, St. Louis, MO, USA). Cells on the underside of Matrigel were counted. Degree of invasion was denoted by the percentage of the number of indicated cells relative to that of Mock cells transfected with si-control.

Statistical analysis. Comparison between two groups was performed using Student's t-test. Correlation between two variables was tested by Pearson's correlation method. Statistical significance was defined as $P$ value $<0.05$. Data represent average values and S.D. (error bars) obtained from three independent experiments.

\section{Conflict of Interest}

The authors declare no conflict of interest.

Acknowledgements. This work was supported by a research grant (1310320) from the National Cancer Center, Korea.

\section{Author contributions}

Conception and design: Y-NK and B-KP; development of methodology: JYS, Y-NK, and B-KP; acquisition of data: all authors; analysis and interpretation of data: JYS, S-YP, Y-NK, and B-KP; writing and review of the manuscript: JYS, Y-NK, and B-KP; technical and material support: all the authors; and study supervision: Y-NK and B-KP.

1. Thiery JP, Sleeman JP. Complex networks orchestrate epithelial-mesenchymal transitions. Nat Rev Mol Cell Biol 2006; 7: 131-142.

2. Iwano M, Plieth D, Danoff TM, Xue C, Okada H, Neilson EG. Evidence that fibroblasts derive from epithelium during tissue fibrosis. J Clin Invest 2002; 110: 341-350.

3. Thiery JP. Epithelial-mesenchymal transitions in tumour progression. Nat Rev Cancer 2002; 2: 442-454.

4. Massague J. TGFbeta in cancer. Cell 2008; 134: 215-230.

5. Shi Y, Massague J. Mechanisms of TGF-beta signaling from cell membrane to the nucleus. Cell 2003; 113: 685-700.

6. Peinado $\mathrm{H}$, Olmeda $\mathrm{D}$, Cano A. Snail Zeb and bHLH factors in tumour progression: an alliance against the epithelial phenotype? Nat Rev Cancer 2007; 7: 415-428.

7. Tamura $T$, Yanai $H$, Savitsky $D$, Taniguchi $T$. The IRF family transcription factors in immunity and oncogenesis. Annu Rev Immunol 2008; 26: 535-584.

8. Tamura T, Nagamura-Inoue T, Shmeltzer Z, Kuwata T, Ozato K. ICSBP directs bipotential myeloid progenitor cells to differentiate into mature macrophages. Immunity 2000; 13: 155-165.

9. Tamura T, Ozato K. ICSBP/IRF-8: its regulatory roles in the development of myeloid cells. J Interferon Cytokine Res 2002; 22: 145-152.

10. Holtschke T, Lohler J, Kanno Y, Fehr T, Giese N, Rosenbauer F et al. Immunodeficiency and chronic myelogenous leukemia-like syndrome in mice with a targeted mutation of the ICSBP gene. Cell 1996; 87: 307-317.

11. Gabriele L, Phung J, Fukumoto J, Segal D, Wang IM, Giannakakou P et al. Regulation of apoptosis in myeloid cells by interferon consensus sequence-binding protein. J Exp Med 1999; 190: 411-421.

12. Lee KY, Geng H, Ng KM, Yu J, van Hasselt A, Cao Y et al. Epigenetic disruption of interferon-gamma response through silencing the tumor suppressor interferon regulatory factor 8 in nasopharyngeal, esophageal and multiple other carcinomas. Oncogene 2008; 27: $5267-5276$.

13. Sung JY, Kim H, Kim YN, Na YS, Park BK. Interferon consensus sequence binding proteininduced cell proliferation is mediated by TGF-beta signaling and p38 MAPK activation. Lab Invest 2011; 91: 1304-1313

14. Rosenbauer F, Kallies A, Scheller M, Knobeloch KP, Rock CO, Schwieger M et al. Disabled-2 is transcriptionally regulated by ICSBP and augments macrophage spreading and adhesion. EMBO J 2002; 21: 211-220.

15. Yang D, Thangaraju M, Greeneltch K, Browning DD, Schoenlein PV, Tamura T et al. Repression of IFN regulatory factor 8 by DNA methylation is a molecular determinant of apoptotic resistance and metastatic phenotype in metastatic tumor cells. Cancer Res 2007; 67: 3301-3309.

16. Liu X. Inflammatory cytokines augments TGF-beta1-induced epithelial-mesenchymal transition in A549 cells by up-regulating TbetaR-I. Cell Motil Cytoskeleton 2008; 65: 935-944.

17. Schiavoni G, Mattei F, Borghi P, Sestili P, Venditti M, Morse HC 3rd et al. ICSBP is critically involved in the normal development and trafficking of Langerhans cells and dermal dendritic cells. Blood 2004; 103: 2221-2228.

18. Micalizzi DS, Wang CA, Farabaugh SM, Schiemann WP, Ford HL. Homeoprotein Six1 increases TGF-beta type I receptor and converts TGF-beta signaling from suppressive to supportive for tumor growth. Cancer Res 2010; 70: 10371-10380.

19. Chambers AF, Groom AC, MacDonald IC. Dissemination and growth of cancer cells in metastatic sites. Nat Rev Cancer 2002; 2: 563-572.

20. Nieto MA, Sargent MG, Wilkinson DG, Cooke J. Control of cell behavior during vertebrate development by Slug, a zinc finger gene. Science 1994; 264: 835-839.

21. Batlle E, Sancho E, Franci C, Dominguez D, Monfar M, Baulida J et al. The transcription factor snail is a repressor of $\mathrm{E}$-cadherin gene expression in epithelial tumour cells. Nat $\mathrm{Cell}$ Biol 2000; 2: 84-89

22. Comijn J, Berx G, Vermassen P, Verschueren K, van Grunsven L, Bruyneel E et al. The two-handed $\mathrm{E}$ box binding zinc finger protein SIP1 downregulates E-cadherin and induces invasion. Mol Cell 2001; 7: 1267-1278.

23. Yang J, Mani SA, Donaher JL, Ramaswamy S, Itzykson RA, Come C et al. Twist, a master regulator of morphogenesis, plays an essential role in tumor metastasis. Cell 2004; 117: 927-939. 
24. Li H, Wang $\mathrm{H}$, Wang $F, G u Q, X u X$. Snail involves in the transforming growth factor beta1mediated epithelial-mesenchymal transition of retinal pigment epithelial cells. PLoS One 2011; 6: e23322.

25. Yin K, Liao Q, He H, Zhong D. Prognostic value of Twist and E-cadherin in patients with osteosarcoma. Med Oncol 2012; 29: 3449-3455.

26. Schmidt M, Nagel S, Proba J, Thiede C, Ritter M, Waring JF et al. Lack of interferon consensus sequence binding protein (ICSBP) transcripts in human myeloid leukemias. Blood 1998; 91: 22-29.

27. Lee HS, Lee HK, Kim HS, Yang HK, Kim WH. Tumour suppressor gene expression correlates with gastric cancer prognosis. J Pathol 2003; 200: 39-46.

28. Wegener J, Keese CR, Giaever I. Electric cell-substrate impedance sensing (ECIS) as a noninvasive means to monitor the kinetics of cell spreading to artificial surfaces. Exp Cell Res 2000; 259: 158-166.
Cell Death and Disease is an open-access journal published by Nature Publishing Group. This work is licensed under a Creative Commons Attribution-NonCommercialShareAlike 3.0 Unported License. The images or other third party material in this article are included in the article's Creative Commons license, unless indicated otherwise in the credit line; if the material is not included under the Creative Commons license, users will need to obtain permission from the license holder to reproduce the material. To view a copy of this license, visit http://creativecommons.org/licenses/ by-nc-sa/3.0/

Supplementary Information accompanies this paper on Cell Death and Disease website (http://www.nature.com/cddis) 